\title{
PENGARUH PELAYANAN ADMINISTRASI AKADEMIK DAN IKLIM ORGANISASI TERHADAP KEPUASAN MAHASISWA FAKULTAS ILMU KESEHATAN UNIVERSITAS MUHAMMADIYAH TANGERANG
}

\author{
Swandi Panggabean ${ }^{1}$, Mustofa Kamil1 ${ }^{2}$ \& Edi Mulyadi ${ }^{3}$ \\ ${ }^{123}$ Program Pascasarjana UNIS Tangerang \\ Email: edmulyadi@unis.ac.id
}

\begin{abstract}
The title of this Research is the Influence of Academic and Clinical Administration Service of the Organization to the Student Satisfaction of Faculty of Health Sciences at Muhammadiyah University of Tangerang. This research was conducted at the Faculty of Health Sciences University of Muhammadiyah with the object of the researchers are all students of the Faculty of Health Sciences Muhammadiyah University of Tangerang. The purpose of this study is to analyze the influence of Academic and Clinical Administrative Services on Student Satisfaction Faculty of Health Sciences Muhammadiyah University of Tangerang. Research is a quantitative study using the method of causal survey, this method uses path analysis (goal analysis) whose purpose is to determine the effect of service Academic administration, and organizational climate with student satisfaction of Faculty of Health Sciences UMT. In order to answer the above problem formulation, this study was conducted with the total population of 528 students, samples taken as many as 228 students by distributing questionnaires to respondents. From the results of research conducted showed that there is a significant influence between academic administration services with student satisfaction with coefficient value 0.801, and there is significant influence between organizational climate to student satisfaction with coefficient value 0.733; And there is a simultaneous influence between academic administration services and organizational climate on student satisfaction. Keywords: Academic administration services, organizational climate, student satisfaction.
\end{abstract}

\section{A. Pendahuluan}

Pendidikan merupakan suatu sarana untuk mengembangkan pengetahuan, kemampuan yang dibutuhkan dalam memajukan Negara, serta dalam menghadapi persaingan global. Sebagai bentuk kepedulian maka Negara menjamin dan mengatur pendidikan warganya yang tertuang dalam UndangUndang Dasar 1945 pasal 31. Sebagai implikasinya, pemerintah memberlakukan wajib belajar sembilan tahun, artinya setiap anak Indonesia wajib menempuh pendidikan minimal hingga jenjang Sekolah Menengah Pertama. Maka tuntutan kebutuhan pendidikan akan semakin tinggi, tidak hanya puas dengan pendidikan sekolah tingkat atas, tetapi akan terus menempuh pendidikan yang lebih tinggi.
Dalam upaya untuk menghasilkan lulusan di bidang kesehatan yang profesional, serta tetap mampu mempertahankan sebagai salah satu Fakultas Ilmu Kesehatan favorite di kota Tangerang, Fakultas Ilmu Kesehatan Universitas Muhammadiyah Tangerang (FIKes UMT) sebagai bagian dari Perguruan Tinggi Muhammadiyah yang menyelenggarakan Pendidikan Tinggi, di bidang kesehatan, yang berdiri sejak tahun 2002, dengan memiliki 4 (empat) prodi, yakni Prodi D-III Kebidanan, D-IV Bidan Pendidik, S-1 Keperawatan dan Program Profesi Ners, dengan jumlah mahasiswa aktif pada tahun Akademik 2016/2017 sekitar 528 (lima ratus dua puluh delapan), Sedangkan jumlah tenaga pendidik \pm 50 (lima puluh) dan 15 (lima belas) jumlah tenaga kependidikan, dalam hal ini terus 
melakukan beberapa usaha untuk dapat memenuhi kebutuhan pelanggannya, yakni mahasiswa, masyarakat dan dunia kerja.

Pada setiap kebijakan atau program yang di terapkan dalam sebuah organisasi pendidikan, terutama Perguruan Tinggi tentu pada prosesnya tidak terlepas dari beberapa kendala yang di hadapi, ini berlaku juga di FIKes UMT, dalam upaya peningkatan mutu layanannya, tetap saja mengalami benturan-benturan yang sedikit banyak menghambat prosesnya, yang pada akhirnya berimbas kepada pelanggan sebagai penerima jasa layanan tersebut, di FIKes UMT, meskipun sistem dan rencana, yang merupakan rancangan awal bagi terselenggaranya mutu layanan yang baik telah di buat, akan tetapi jika tidak di ikuti dengan penyesuaian dan peningkatan sumber daya manusianya itu sendiri, dalam proses pelaksanaannya sepertinya tidak menutup kemungkinan akan menemui beberapa kendala, sehingga apa yang menjadi tujuan awal dan yang di kehendaki bersama, akan sulit untuk terwujud sebagaimana yang di inginkan. Karena dalam upaya untuk meningkatkan mutu layanan pendidikan, di haruskan adanya beberapa hal seperti profesionalnya tenaga penunjang dalam hal ini administrasi (keuangan, akademik dan umum), prosedur layanan yang mudah dan efisien serta di tunjang oleh sarana dan prasarana yang memadai. Sedangkan, apakah memungkinkan terciptanya tenaga kependidikan yang handal sehingga layanan yang di berikan memuaskan pelanggan, jika tidak adanya usaha untuk meningkatkan pengembangan kemampuan, memfasilitasi pengembangan keterampilan, melalui kegiatan-kegiatan yang hasilnya nanti di anggap sesuai serta mampu dalam menunjang kinerja dan tanggung jawabnya menjadi lebih baik.

Penerapan teknologi informasi diperguruan tinggi merupakan salah satu bentuk dari perubahan dalam proses pelayanan administrasi akademik kepada mahasiswa agar dalam proses registrasi kemahasiswaan lebih efektif dan efisien.
Dalam kaitan penggunaan teknologi informasi terhadap pengelolaan dokumen administrasi akademik kemahasiswaan , FIKes UMT telah melakukan perubahan sistem administrasi akademik dari sistem pengelolaan dokumen yang bersifat manual menuju sistem pengelolaan administrasi akademik kemahasiswaan berbasis SIAKAD (Sistem Informasi Akademik), yaitu pengelolaan administrasi dokumen perkantoran berbasis teknologi informasi melalui jaringan internet.

Bagian administrasi akademik Fakultas langsung berhadapan dengan mahasiswa, sehingga layanan admininstrasi akademik perlu mendapatkan perhatian yang lebih agar dapat memberikan kepuasan yang optimal bagi mahasiswa. Namun demikian sampai sekarang masih sering diketahui adanya keluhan-keluhan dari para mahasiswa untuk beberapa alasan yang meliputi masalah teknis maupun non teknis. Masalah teknis misalnya pelayanan kurang ditanggapi dengan cepat, penggunaan ruang kuliah yang bersamaan dalam satu waktu pada awal periode kuliah, daftar absensi yang belum lengkap disebabkan keterlambatan dalam pengumpulan KRS ke dosen wali, penjaga layanan referensi yang tidak berjaga karena sedang mengawasi ujian, komputer penelurusan Sistem Informasi Akademik (SIAKAD) yang sering ngadat bahkan mati; masalah non teknis misalnya : penampilan pegawai kurang menarik, pegawai kurang ramah dalam melayani mahasiswa, tidak optimalnya penggunaan kelas laboratorium

Pelayanan pendidikan bukan hanya pada pelayanan administrasi akademik saja akan tetapi dosen pun harus mampu memberikan pelayanan terhadap mahasiswanya, salah satunya dalam proses pembelajaran dengan menciptakan iklim atau suasana belajar yang kondusif untuk mendukung kualitas proses pembelajaran. Pengelolaan kelas yang baik dapat mendukung terciptanya atmosfir belajar yang kondusif, kehangatan dan keantusiasan yang mengarah pada hal hal 
yang positif, yang pada akhirnya suasana akan lebih menyenangkan, mengasyikkan mencerdaskan, menguatkan menghidupkan dan memberi kebebasan yang bertanggung jawab. Atmosfir atau iklim yang tercipta dalam interaksi belajar di kelas memegang peranan penting dalam menstimulasi dan mempertahankan keterlibatan mahasiswa dalam belajar. Karena itu dosen perlu menciptakan iklim organisasi yang dapat membangkitkan komunikasi dan interaksi dalam kelas sehingga tujuan pembelajaran tercapai secara maksimal.

\section{KAJIAN PUSTAKA}

\section{A. Kepuasan Mahasiswa}

Menurut Sugito kepuasan mahasiswa adalah suatu keadaan terpenuhinya keinginan, harapan, dan kebutuhan mahasiswa (dalam Srinadi, 2008). Sementara Sarjono (2007) kepuasan mahasiswa adalah perbandingan antara harapan yang diinginkan mahasiswa tentang pelayanan karyawan, kompetensi dosen yang didukung oleh sarana prasarana dan kepemimpinan dengan apa yang mahasiswa rasakan setelah mendapatkan pelayanan.

B. Pelayanan Administrasi

Sedangkan menurut Groonros (1990:27) dalam Ratminto dan Atik (2005:2) pelayanan adalah suatu aktivitas atau serangkaian aktivitas yang bersifat tidak kasat mata (tidak dapat diraba) yang terjadi sebagai akibat adanya interaksi antara konsumen dengan karyawan atau hal-hal lain yang di sediakan oleh perusahaan pemberi pelayanan yang dimaksudkan untuk memecahkan permasalahan konsumen atau pelanggan.

Sedangkan dalam pengertian sempit, seperti yang disampaikan oleh Soewarno Handayaningrat (1996: 2) bahwa administrasi adalah suatu kegiatan yang meliputi catat mencatat, surat menyurat, pembukuan ringan, ketik mengetik, agenda dan sebagainya yang bersifat ketatausahaan.

C. Iklim Organisasi
Para pakar memberikan definisi iklim organisasi secara beragam. Menurut Newstrom \& Davis (1996: 21), iklim organisasi adalah lingkungan manusia yang di dalamnya para pegawai suatu organisasi melakukan pekerjaaan mereka. Dari pengertian ini tampak bahwa iklim organisasi menyangkut semua lingkungan yang ada atau yang dihadapi oleh pegawai yang berada dalam suatu organisasi yang mempengaruhi pegawai dalam melaksanakan tugas-tugas keorganisasiannya.

D. Kerangka Berfikir dan Hipotesis

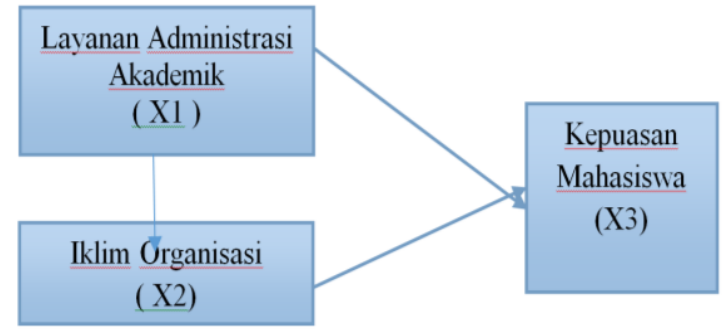

Jadi hipotesis juga dapat dinyatakan sebagai jawaban teoritis terhadap rumusan masalah penelitian, belum jawaban yang empirik.

Seiring dengan pengertioan tersebut diatas serta sesuai dengan rumusan masalah dan tujuan penelitian, maka hipotesis yang diajukan dalam penelitian ini adalah bahwa diduga :

1. Terdapat pengaruh pelayanan administrasi akademik terhadap kepuasan mahasiswa FIKes UMT

2. Terdapat pengaruh iklim organisasi terhadap kepuasan mahasiswa FIKes UMT

3. Terdapat pengaruh secara simultan antara pelayanan administrasi akademik dan iklm organisasi terhadap kepuasan mahasiswa di FIKes UMT

\section{B. Metode Penelitian}

Jenis penelitian yang digunakan adalah metode penelitian kuantitatif dengan menggunakan analisis jalur yaitu : merupakan suatu metode penelitian yang utamanya digunakan untuk mengetahui hubungan sebab akibat, dengan tujuan menerangkan akibat langsung akibat tidak 
langsung seperangkat variabel, sebagai variabel penyebab terhadap lainnya yang merupakan variabel akibat.

Metode analisis data yang digunakan dalam penelitian ini adalah analisis jalur ( path analysis ) karena penliti ingin memastikan apakah ada pengaruh antara Pelayanan administrasi akademik dan iklim organisasi terhadap kepuasan mahasiswa.

Model analisis jalur adalah sebagai berikut

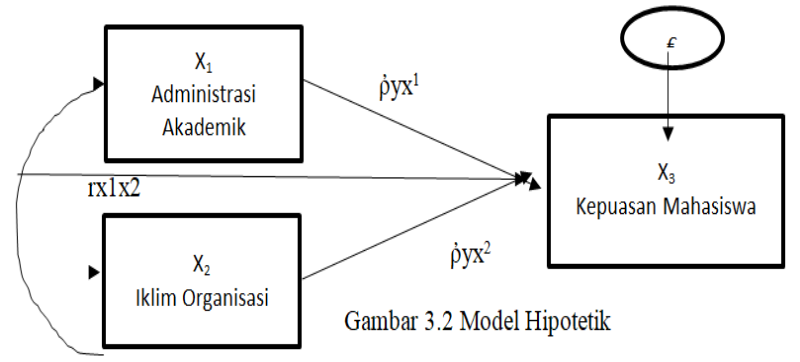

Ilmu $\begin{array}{cc}\text { Penelitian ini dilakukan di Fakultas } \\ \text { Kesehatan }\end{array}$

Muhammadiyah Tangerang, dengan pengambilan sampel penelitian ini berjumlah 228 orang mahasiswa, Dalam penelitian ini penulis menggunakan skala likert. Skala ini melibatkan pernyataan yang berkaitan dengan sikap responden. Data primer sebagai data utama yang akan dianalisis diperoleh langsung dilapangan dari responden penelitian.

Penelitian ini menggunakan diagram jalur untuk menyatakan model yang dianalisis, dalam analisis jalur juga ditampilkan dalam bentuk persamaan yang biasa disebut persamaan struktural. Persamaan struktural menggambarkan hubungan sebab akibat antar varaibel yang diteliti yang dinyatakan dalam bentuk persamaan matematis.

$$
\mathrm{Y}=\mathrm{P}_{\mathrm{yx}} \mathrm{X}_{1}+\mathrm{P}_{\mathrm{yx}} \mathrm{X}_{2}+\mathrm{P}_{\mathrm{yx} \epsilon}
$$

\section{Hasil Penelitian Dan Pembahasan Hasil Penelitian}

Hasil Uji Validitas dan Reabilitas pada variabel X1, X2 dan Y menunjukan data yang valid dan reliabel. Uji asumsi SEM ditujukan untuk melihat apakah prasyarat yang diperlukan dalam permodelan dapat terpenuhi . prasyarat yang harus dipenuhi adalah asumsi multivariate normal, tidak adanya multikolinieritas atau singularitas, dan outliers.

\section{1) Uji normalitas}

ntuk menguji ada atau tidaknya asumsi normalitas, maka dapat dilakukan dengan nilai statistik $\mathrm{z}$ untuk skewness dan kurtosisnya secara empirik dapat dilihat pada Critical Ratio (CR) yang digunakan tingkat signifikansinya 5\%, maka nilai CR yang berada diantara -1,96 sampai dengan 1,96 $(-1,96 \leq \mathrm{CR} \leq 1,96)$ dikatakan data berdistribusi normal, baik secara univariat maupun secara multivariate. Hasil pengujian normalitas pada tabel diatas diperoleh nilai CR sebesar -1,261 yang berarti CR berada diantara -1,96 sampai dengan 1,96. Sehingga dapat dinyatakan bahwa data multivariate normal. Selain itu juga data univariat normal ditunjukkan oleh semua critical ratio semua indikator terletak diantara $-1,96 \leq \mathrm{CR} \leq 1,96$.

\section{2) Uji Multikolinieritas}

Multikolineritas dapat dilihat melalui determinan matriks kovarians. Nilai determinan yang sangat kecil atau mendekati nol, menunjukkan indikasi terdapatnya masalah multikolineritas atau singularitas, sehingga data tersebut tidak dapat digunakan untuk penelitian. Berdasarkan data diatas hasil pengujian multikolinieritas memberikan nilai Determinant of sample covariance matrix sebesar 537.573. nilai ini jauh dari nol, sehingga disimpulkan bahwa data tidak terdapat masalah multikolinieritas atau singularitas pada data yang dianalisis sehingga dapat dilanjutkan pada penelitian ini

\section{3) Uji Outliers}

Outliers adalah observasi yang muncul dengan nilai ekstrim baik secara univariat maupun secara multivariat yaitu muncul karena adanya kombinasi karakteristik unik yang dimiliki dan terlihat sangat jauh berbeda dari observasi- observasi lainnya. Apabila terjadi outliers dapat dilakukan 
perlakuan khusus pada outliers-nya asalkan diketahui bagaimana munculnya outliers tersebut. Deteksi terhadap multivariate outliers dilakukan dengan memperhatikan nilai Mahalanobis Distance. Kriteria yang digunakan adalah berdasarkan nilai Chi Square pada derajat kebebasan (degree of freedom) sebesar jumlah variabel indikator pada tingkat signifikansi $\mathrm{p}<0,05$.

Hasil uji outliers dalam penelitian ini tidak terlihat angka pada p2 yang kurang dari 0.05. hal ini membuktikan tidak adanya data yang dianggap outliers. Walaupun ada data yang yang jaraknya cukup besar yaitu 31.324 namun jarak tersebut masih dapat ditoleransi sehingga tidak dianggap data outliers.

\section{4) Metode analisis regresi dengan pendekatan konfirmatori}

Metode analisis regresi dengan pendekatan konfirmatori ini digunakan untuk mengetahui pengaruh variabel Pelayanan Administrasi Akademik $\left(X_{1}\right)$ dan variabel Iklim Organisasi $\left(X_{2}\right)$ terhadap Kepuasan mahasiswa (X3). hasil pengujian dengan program AMOS memberikan hasil model regresi dengan pendekatan konfirmatori seperti terlihat pada gambar berikut :

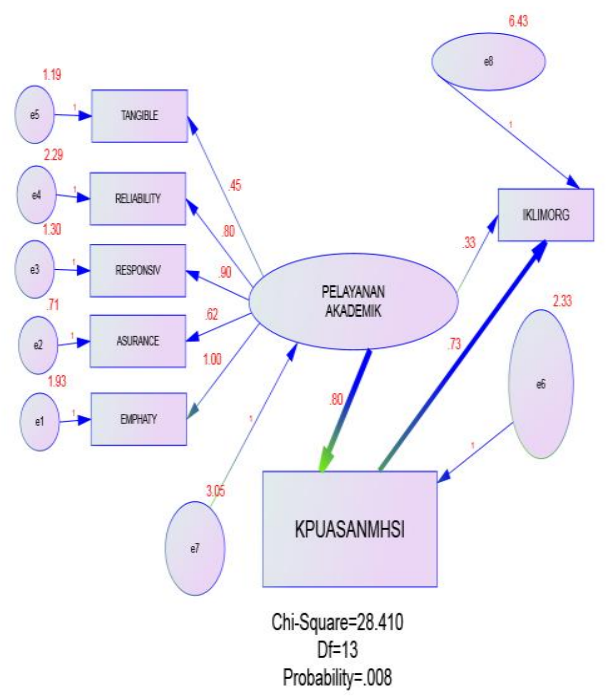

5) Hasil Pengukuran Tingkat Kesesuaian (goodness of-fit model )

\begin{tabular}{|c|c|c|}
\hline $\begin{array}{c}\text { Ukuran } \\
\text { Goodness } \\
\text { of Fit }\end{array}$ & $\begin{array}{c}\text { Batas Penerimaan } \\
\text { Goodness Of Fit }\end{array}$ & Hasil \\
\hline $\begin{array}{c}\text { Chi } \\
\text { Square }\end{array}$ & $\begin{array}{c}\text { Semakin kecil } \\
\text { semakin baik }\end{array}$ & 28.410 \\
\hline RMSEA & $0,05 \leq \mathrm{RMSEA} \leq 0,08$ & 0,072 \\
\hline TLI & $0,80 \leq \mathrm{GFI} \leq 1$ & 0,964 \\
\hline CFI & $0,80 \leq \mathrm{GFI} \leq 1$ & 0,977 \\
\hline NFI & $0,80 \leq \mathrm{GFI} \leq 1$ & 0,960 \\
\hline
\end{tabular}

Sumber : hasil olah data 2017

Berdasarkan hasil pengolahan data dan kriteria penerimaan pengujian goodness of fit tes model berdasarkan ukuran kecocokan absolut yang menentukan drajat prediksi model keseluruhan ( model structural keseluruhan ) terhadap matrik korelasi dank ovarian adalah baik.hal ini terlihat dari nilai chi square 28.410 dimana semakin kecil nilai chi square maka semakin cocok model tersebut. Dan nilai root mean square error of approximation ( RMSEA) 0,072 menunjukan RMSEA yang fit karena 0,072 berada diantara 0,05 dan 0,08 .

Sedangkan berdasarkan kecocokan incremental yaitu membandingkan model yang diusulkan dengan model dasar ( baseline model ) juga sangat baik karena normal fit index ( NFI ) bernilai 0,960 atau bias disebut good fit. Demikian juga nilai Tucker-Lewis Index ( TLI ) sebesar 0,964 termasuk kedalam kriteria good fit, sehingga secara keseluruhan model persamaan analisis jalur yang digunakan dapat diterima dan pengujian hipotesa dapat dilanjutkan.

\section{6) Uji Hipotesis}

Berdasarkan hasil pengolahan dengan dengan program AMOS tersebut diperoleh nilai hasil regression weight seperti pada tabel 4.27, dari hasil pengolahan data dapat dilihat bahwa semua variable berpengaruh secara signifikan, dengan demikian uji hipotesis dapat diartikan seperti dibawah ini : 
a. Uji hipotesis 1

$\mathrm{H}_{0}$ : tidak terdapat pengaruh antara variable pelayanan administrasi akademik dengan kepuasan mahasiswa

$\mathrm{H}_{1}$ : terdapat pengaruh antara variabel administrasi akademik dengan kepuasan mahasiswa

Dari dugaan tersebut setelah diuji ternyata terbukti bahwa koefisien variable pelayanan administrasi akademik adalah 0,801. Pengaruh pelayanan administrasi akademik signifikan secara statistik karena diketahui bahwa signifikansi variable pelayanan administrasi akademik sebesar 0,000 lebih kecil dari 0.05, maka $\mathrm{H}_{0}$ ditolak yang berarti ada pengaruh yang signifikan dari variable pelayanan administrasi akademik terhadap kepuasan mahasiswa.

b. Uji Hipotesis 2

$\mathrm{H}_{0}$ : tidak terdapat pengaruh antara variable Iklim Organisasi dengan kepuasan mahasiswa

$\mathrm{H}_{1}$ : terdapat pengaruh antara variabel Iklim Organisasi dengan kepuasan mahasiswa

Dari dugaan tersebut setelah diuji ternyata terbukti bahwa koefisien variable Iklim Organisasi adalah 0,733. Pengaruh iklim organisasi signifikan secara statistik karena diketahui bahwa signifikansi variable iklim organisasi sebesar 0,000 lebih kecil dari 0.05, maka $\mathrm{H}_{0}$ ditolak yang berarti ada pengaruh yang signifikan dari variabel iklim organisasi akademik terhadap kepuasan mahasiswa.

c. Uji Hipotesis 3

$\mathrm{H}_{0}$ : tidak terdapat pengaruh antara variabel Pelayanan Administrasi akademik dan Iklim Organisasi dengan kepuasan mahasiswa

$\mathrm{H}_{1}$ : terdapat pengaruh antara variabel Pelayanan Administrasi akademikdan Iklim Organisasi dengan kepuasan mahasiswa

Dari dugaan tersebut setelah diuji ternyata terbukti bahwa koefisien variabel pelayanan administrasi akdademik adalah 0,131 dan nilai $\mathrm{B}=$ 0,450 dengan tingkat signifikansi 0,000 dan variabel Iklim Organisasi adalah 0,250 . Serta nilai $B=0,387$ dengan tingkat signifikansi 0,000 . secara statistik karena diketahui bahwa signifikansi kedua variabel tersebut adalah 0,000 lebih kecil dari 0.05, maka $\mathrm{H}_{0}$ ditolak yang berarti ada pengaruh yang signifikan antara variabel pelayanan administrasi akademik dan iklim organisasi akademik terhadap kepuasan mahasiswa.

\section{7) Hasil Uji Signifikansi Simultan ( Uji Statistik F )}

\begin{tabular}{|c|c|c|c|c|c|}
\hline \multicolumn{6}{|c|}{ ANOVA $^{a}$} \\
\hline Model & $\begin{array}{l}\text { Sum } \\
\text { of } \\
\text { Squar } \\
\text { es }\end{array}$ & $\begin{array}{l}\mathrm{D} \\
\mathrm{f}\end{array}$ & $\begin{array}{l}\text { Mean } \\
\text { Squar } \\
\mathrm{e}\end{array}$ & $\mathrm{F}$ & Sig \\
\hline $\begin{array}{l}1 \text { Regress } \\
\text { ion }\end{array}$ & $\begin{array}{r}502,8 \\
47\end{array}$ & 2 & $\begin{array}{r}251,4 \\
23\end{array}$ & $\begin{array}{r}119,0 \\
57\end{array}$ & $\begin{array}{r}, 00 \\
0^{\mathrm{b}}\end{array}$ \\
\hline Residua & 475,1 & 22 & 112 & & \\
\hline 1 & 53 & 5 & 2,112 & & \\
\hline Total & $\begin{array}{r}978,0 \\
00\end{array}$ & $\begin{array}{r}22 \\
7\end{array}$ & & & \\
\hline
\end{tabular}

a. Dependent Variable: Kepuasan

Mahasiswa

b. Predictors: (Constant), Iklim

Organisasi, Pelayanan Administrasi

Akademik

Berdasarkan tabel diatas, diperoleh nilai $\mathrm{F}$ hitung sebesar 119.057 dengan nilai signifikan 0,000. Nilai signifikan yang diperoleh jauh lebih kecil dari nilai $\alpha$ yang ditentukan 0.05 yang berarti bahwa terdapat pengaruh yang positif, dan sebaliknya jika nilai signifikansi yang diperoleh lebih besar dari 0.05 berarti tidak terdapat pengaruh positif antara variabel bebas ( Pelayanan administrasi akademik dan iklim organisasi ) terhadap variabel terikat ( kepuasan mahasiswa ) dengan demikian dapat diambil kesimpulan bahwa model linier yang digunakan sudah tepat. Hal ini menunjukan bahwa model tersebut 
menjelaskan atau menerangkan pengaruh pelayanan administrasi akademik dan iklim organisasi terhadap kepuasan mahasiswa.

Dalam pengambilan keputusan berdasarkan nilai $\mathrm{F}$ hitung dan $\mathrm{F}$ tabel, bahwa diketahui nilai $\mathrm{F}$ hitung $119.057>$ dari $\mathrm{F}$ tabel 3.04, maka dapat ditarik kesimpulan bahwa variabel bebas $\mathrm{X} 1$ dan $\mathrm{X} 2$ ( secara simultan ) berpengaruh terhadap variabel terikat ( X3 ).

\section{Pembahasan}

Indikator yang tercakup dalam variabel X1 adalah Tangible ( bukti fisik ), Reliability ( kehandalan ), Responsiveness ( daya tanggap ), Assurance ( Jaminan ) dan Empathy ( empati ) dari indikatorindikator tersebut yang tercakup pada variabel X1 menjelaskan bahwa responden lebih dominan memberikan penrnyataan Baik yaitu $72 \%$ untuk indikator Tangibel, $58,35 \%$ untuk indikator reliability, $60,32 \%$ untuk indikator responsiveness, 62,3\% untuk indikator Assurance dan 64,38\% untuk indikator Empathy, selebihnya mereka memberikan pernyataan sangat baik, tidak baik dan sangat tidak baik. Artinya variabel pelayanan administrasi akademik sangat berpengaruh terhadap kepuasan mahasiswa.

Dari nilai koefisien jalur variabel pelayanan administrasi akademik terhadap kepuasan mahasiswa adalah sebesar 0,801, jumlah ini menunjukan bahwa variabel pelayanan administrasi akademik memiliki pengaruh terhadap kepuasan mahasiswa FIKes UMT sebesar 80,1\%. Besarnya pengaruh ini dapat dijelaskan semakin tinggi tingkat pelayanan administrasi akademik yang diberikan pegawai maka mahasiswa akan semakin puas. Dengan demikian untuk meningkatkan pelayanan administrasi akademik perlu adanya pelatihan-pelatihan terhadap staf akademik agar pelayanan terhadap mahasiswa lebih baik lagi dan bias ditingkatkan sesuai dengan tingkat kebudayaan yang berbeda dari masa ke masa, sehingga dengan demikian tingkat kepuasan mahasiswa tetap bias dipertahankan dan bisa ditingkatkatan. Dengan meningkatnya tingkat pengetahuan dan keterampilan staf akademik diharapkan mahasiswa bisa menjadi duta Universitas dalam menyampaikan kepuasannya kepada calon mahasiswa berikutnya.

Indikator yang tercakup dalam variabel iklim organisasi (X2) adalah ruangan yang nyaman, lingkungan belajar yang bersih, ruang belajar yang bebas dari kebisingan, keharmonisan lingkungan, hubungan dosen dengan mahasiswa, alatalat pembelajaran terpelihara dengan baik, tingkat ketanggapan pimpinan, dan mahasiswa bebas dalam memilih organisasi dari indikator-indikator tersebut yang tercakup pada variabel X2 menjelaskan bahwa responden memberikan penrnyataan Baik yaitu sebesar $58,5 \%$, pernyataan sangat baik sebesar $3,7 \%$ pernyataan tidak baik sebesar $31,83 \%$ dan pernyataan sangat tidak baik sebesar 5,9\% Artinya iklim organisasi begitu sangat berpengaruh terhadap kepuasan mahasiswa, dilihat dari jumlah persentase antara pernyataan baik dan tidak baik mempunyai perbedaan yang sangat tipis meskipun lebih dominan kepada pernyataan baik, maka dari itu indikator-indikator yang ada pada variabel iklim organisasi perlu dievaluasi oleh pihak institusi agar lebih ditingkatkan lagi sehingga mahasiswa menjadi lebih puas. sikap-sikap negative para pegawai, dosen dan pimpinan serta fasilitas pembelajaran dapat diperbaiki agar kepuasan mahasiswa serta penilaian tidak baik bisa menjadi lebih baik.

Dari nilai koefisien jalur variabel Iklim organisasi terhadap kepuasan mahasiswa adalah sebesar 0,733 , jumlah ini menunjukan bahwa variabel iklim organisasi memiliki pengaruh terhadap kepuasan mahasiswa FIKes UMT sebesar $73,3 \%$. Besarnya pengaruh ini dapat dijelaskan semakin tinggi tingkat iklim organisasi yang ada di FIKes UMT maka mahasiswa akan semakin puas. 
Dilihat hasil uji simultan ( uji $\mathrm{F}$ ) bahwa diperoleh nilai $\mathrm{F}$ hitung sebesar 119.057 dengan nilai signifikan 0,000. Nilai signifikan yang diperoleh jauh lebih kecil dari nilai $\alpha$ yang ditentukan 0.05 yang berarti bahwa terdapat pengaruh yang positif, Dalam pengambilan keputusan berdasarkan nilai $\mathrm{F}$ hitung dan $\mathrm{F}$ tabel, bahwa diketahui nilai $\mathrm{F}$ hitung 119.057 > dari $\mathrm{F}$ tabel 3.04, maka dapat ditarik kesimpulan bahwa variabel bebas X1 dan X2 ( secara simultan ) berpengaruh terhadap variabel terikat ( X3 ).

\section{Kesimpulan Dan Rekomendasi}

Berdasarkan hasil penelitian dan pembahasan yang telah diuraikan pada bab sebelumnya, maka dapat diambil kesimpulan bahwa engaruh variabel pelayanan administrasi akademik (X1) terhadap kepuasan mahasiswa (X3) memiliki koefisien regresi 0,801. Dari nilai koefisien variabel pelayanan administrasi akademik terhadap kepuasan mahasiswa adalah sebesar 0,801, koefisien ini menunjukan bahwa jika variabel pelayanan administrasi akademik naik satu unit maka kepuasan mahasiswa FIKes UMT naik sebesar 0,801 unit. Besarnya pengaruh ini dapat dijelaskan semakin tinggi tingkat pelayanan administrasi akademik yang diberikan pegawai maka mahasiswa akan semakin puas. Pengaruh variabel iklim organisasi (X2) terhadap kepuasan mahasiswa (X3) memiliki koefisien regresi 0,733. Dari nilai koefisien variabel iklim organisasi terhadap kepuasan mahasiswa adalah sebesar 0,733, koefisien ini menunjukan bahwa jika variabel iklim organisasi naik satu unit maka memiliki pengaruh terhadap kepuasan mahasiswa FIKes UMT naik sebesar 0,733 unit.. Besarnya pengaruh ini dapat dijelaskan bahwa semakin kondusif tingkat iklim organisasi yang ada di FIKes UMT maka mahasiswa akan semakin puas. Dilihat hasil uji simultan ( uji $\mathrm{F}$ ) bahwa diperoleh nilai $\mathrm{F}$ hitung sebesar 119.057 dengan nilai signifikan 0,000. Nilai signifikan yang diperoleh jauh lebih kecil dari nilai $\alpha$ yang ditentukan 0.05 yang berarti bahwa terdapat pengaruh yang positif, Dalam pengambilan keputusan berdasarkan nilai $\mathrm{F}$ hitung dan $\mathrm{F}$ tabel, bahwa diketahui nilai F hitung $119.057>$ dari $F$ tabel 3.04, maka dapat ditarik kesimpulan bahwa variabel bebas X1 dan X2 ( secara simultan ) berpengaruh terhadap variabel terikat ( X3 ).

Mengacu pada kesimpulan diatas, maka dapat diberikan rekomendasi peningkatan pelayanan administrasi akademik dan iklim organisasi perlu adanya pelatihan-pelatihan terhadap staf akademik agar pelayanan terhadap mahasiswa lebih baik lagi dan bisa ditingkatkan sesuai dengan tingkat kebudayaan yang berbeda dari masa ke masa, sehingga dengan demikian tingkat kepuasan mahasiswa tetap bisa dipertahankan dan bisa ditingkatkatan. Dengan meningkatnya tingkat pengetahuan dan keterampilan staf akademik diharapkan mahasiswa bisa menjadi duta Universitas dalam menyampaikan kepuasannya kepada calon mahasiswa berikutnya. Sedangkan peningkatan yang terkait dengan iklim organisasi terutama peningkatan fasilitas sarana prasarana dan media pembelajaran yang ada di FIKes UMT, yang pada saat masih banyak kekurangan, sehingga perlu ketanggapan dari pihak pimpinan agar mahasiswa FIKes merasa puas atas kualitas jasa secara keseluruhan.

Bagi peneliti selanjutnya, diharapkan mampu mengembangkann metode dalam pengambilan sampel oleh karena itu, nantinya hasil penelitian yang selanjutnya dapat memberikan generalisasi yang lebih kuat dan memperluas jangkauan penelitian yang ada, sehingga penelitian selanjutnya dapat lebih dikembangkan dan diperoleh hasil yang lebih baik dan menyempurnakan penelitian ini dengan menggunakan lebih banyak variabel yang akan dianalisis agar memberikan nilai yang lebih tinggi sehingga dapat 
dihasilkan perbedaan dengan hasil penelitian pada calon mahasiswa tahun 2017.

\section{E. Daftar Pustaka}

Alma B dan Hurriyati R. 2008. Manajemen Corporate \& Strategi Pemasaran Jasa Pendidikan. Bandung: Alfabeta.

Alma B, 2009. Dasar-Dasar Bisnis dan Pemasaran. Bandung: Alfabeta.

Arimawati, R., \& DJASTUTI, I. (2013). Pengaruh Kualitas Pelayanan Kinerja Pegawai Administrasi Akademik Terhadap Kepuasan Mahasiswa Fakultas Ekonomika Dan Bisnis Universitas Diponegoro (Doctoral dissertation, Fakultas Ekonomika dan Bisnis). Diakses pada tanggal 13 April 2017

Angipora, Marius P. 1999. Dasar-dasar Pemasaran. Jakarta: PT Raja Grafindo Persada.

Atmaja L. Setia, Ph.D. 2009. Statistika untuk bisnis dan ekonomi. Yogyakarta: Andi.

Athiyaman, A. (1997). Linking student satisfaction and service quality perceptions: the case of university education. European Journal of Marketing, 31(7), 528-540. Diakses pada tanggal 14 April 2017

Boyd, Walker dan Larreche. 1998. Manajemen Pemasaran Suatu Pendekatan Strategis dengan Orientasi Global. Alih Bahasa Imam Nurmawan. Jakarta: Erlangga.

Brent Davies, Linda Ellison. 1997. Strategic Marketing For School, Financial Times, 128 Long Acre, London: Pitman Publishig. Alih Bahasa Institut Terjemah Negara Malaysia Berhad.

Buku Pedoman Penulisan Tesis. 2017. Program Pasca Sarjana UNIS Tangerang,

Buku Pedoman Akademik, Fakultas Ilmu Kesehatan Universitas
Muhammadiyah Tangerang, 2016/2017

Charles W.Lamb, Joseph F. Hair, Carl Mcdaniel. 2001. Pemasaran. Edisi. Pertama, Alih Bahasa David Oktavia. Jakarta: Salemba Empat.

C.M. Lingga Purnama, 2002. Strategic Marketing Plan. Jakarta: Gramedia Pustaka Utama.

Douglas, J., Douglas, A., \& Barnes, B. (2006). Measuring student satisfaction at a UK university. Quality assurance in education, 14(3), 251-267. Diakses pada tanggal 15 April 2017.

Engel, F.James, Roger D.Blackwell, and Paul W.Miniard. 1995. Perilaku Konsumen. Terjemahan Alex Budianto. Edisi Keenam. Jilid 2. Jakarta : Bina Rupa Aksara.

Gitosudarmo I, 2000. Manajemen Pemasaran. Yogyakarta:BPFE,

Ghozali, Imam, 2013. Aplikasi Analisis Multivariat dengan Program IBM SPSS 21. Edisi 7, Penerbit Universitas Diponegoro, Semarang.

Ign. Sukamdiyo. 1996. Manajemen Koperasi.. Jakarta: Erlangga.

Karemera, D., Reuben, L. J., \& Sillah, M. R. (2003). The effects of academic environment and background characteristics on student satisfaction and performance: The case of South Carolina State University's School of Business. College Student Journal, 37(2), 298-309. Diakses pada tanggal 14 April 2017

Keegan, Warren J, and Mark, 1997. Principle of Global Marketing, Engle wood. Alih Bahasa Alexander Sindoro dan Susanto Budhidarmono.

Kertajaya H, 1996. Marketing Plus 2000 siasat memenangkan persaingan global. Jakarta: PT. Gramedia Pustaka Utama.

Kotler Philip, Armstrong Gary, 1997, 2002. Dasar-dasar Pemasaran 
Jilid I, Edisi Bahasa Indonesia dari Principle of Marketing 7e. Alih Bahasa Alexander Sindoro. Jakarta: Prenhallindo.

Kotler Philip, Keller K Lane. 2007. Manajemen Pemasaran Edisi 12 Jilid 2. Alih Bahasa Benyamin Molan. Jakarta: PT. Indeks.

Kotler Philip, 2006. Manajemen Pemasaran Edisi Milenium, Jilid I. Alih Bahasa Benyamin Molan. Jakarta: Prenhallindo.

Lovelock, Christopher. 1991. Service Marketing and Management. New Jersey: Prentice Hall. Alih Bahasa Agus Widyanto.

Lupiyoadi R, 2006. Manajemen Pemasaran Jasa ( Edisi II ), Jakarta: Salemba Empat.

Malik, M. E., Danish, R. Q., \& Usman, A. (2010). The impact of service quality on students' satisfaction in higher education Institutes of Punjab. Journal of Management Research,2(2), 1.diakses pada tanggal 14 April 2017

Mc.Carthy, E-Jerome dan Wiliam D.Pereault Jr. 2004. Dasar-Dasar Pemasaran, Edisi Bahasa Indonesia. Alih Bahasa Agus Maulana. Jakarta : Penerbit Erlangga.

Payne A, 1993. Book Reviews: The Essence of Services Marketing : by Prentice Hall, Hemel Hempstead

Purnama, Lingga. 2001. Strategi Marketing Plan. Jakarta: PT. Gramedia Pustaka Utama.

Richard L. Daft. 2002. Manajemen Edisi Kelima, Jilid I. Alih Bahasa Emil Salim dkk. Jakarta: Erlangga.

Riduawan 2005. Metode dan Teknik Menyusun Tesis. Bandung Alfabeta

Robbins, Stephen dan Mary coulter. 2007. Management, 8th Edition. New York : Prentice Hall. Alih Bahasa Harry Slamet. Jakarta : Publisher Indeks.

Saladin Dj, 2001. Manajemen Pemasaran, Analisis, Perencanaan,
Pelaksanaan dan Pengendalian.

Bandung: Penerbit :Lindakarya.

Singaribun \& Effendi. 1995. Aplikasi

Statistik Penelitian. Bandung: Alpabeta.

Singgih Santoso.2011. Structural Equation Modeling ( SEM ) Konsep dan Aplikasi dengan Amos 18. Jakarta. PT Elex Media Komputindo.

Solihin Ismail, 2010. Pengantar Manajemen. Jakarta: Erlangga.

Sucherly, 1999. Peranan Manajemen Pemasaran Strategic Dalam Menciptakan Keunggulan Posisional. Bandung : Rosada Karya.

Sugiyono. 2003. Metode Penelitian Administrasi. Bandung: Alfabeta.

2011. Metode

Penelitian Kuantitatif, Kualitatif dan $R \& D$, Bandung: Alfabeta.

Supranto J, 2011. Pengukuran Tingkat Kepuasan Pelanggan Untuk Menaikan Pangsa Pasar. Jakarta: Rineka Cipta.

Susanto, H. (2015). Pengaruh Layanan Akademik Terhadap Kepuasan Mahasiswa Program Pascasarjana Universitas Terbuka Pada Unit Program Belajar Jarak Jauh (UPBJJ) Mataram. Jurnal Pendidikan Terbuka Dan Jarak Jauh, 15(2), 88-98. Diakses pada tanggal 13 April 2017

(Studi tentang Persepsi Siswa SMA Negeri 1 Sukawati). Jurnal Administrasi Puspayani, D. N. (2012). Kontribusi Sarana Prasarana, Layanan Administratif, Kompetensi Profesional Guru terhadap Kepuasan Belajar Pendidikan, 3(2). Diakses pada tanggal 14 April 2017.

Tjiptono F. 2008. Strategi Pemasaran, Edisi III. Yogyakarta: Andi.

Umar Husein, 2002.Riset Pemasaran \& Perilaku Konsumen. Jakarta: PT. Gramedia Pustaka Utama. 
Umar Husain, 2003. Riset Pemasaran \& Perilaku Konsumen. Jakarta: PT. Gramedia Pustaka Utama.

Wiliam J.Stanton. 1996. Fundamental of Marketing, Five Edition, Tokyo: Mc.Graw-Hill, Kogakusha, Ltd. Alih Bahasa Yohanes Lamarto.

Winardi. 1990. Asas-asas manajemen. Bandung: Mandar Maju.

Zeithaml, Valarie A, A Parasuraman, \& Leonard R. Berry. 1990. Delivering Qulity Service, Balancing Customer Perseptio and Expeqtations The Free Press, A, Division, Alih Bahasa Hendra Teguh dkk ( Di unduh tanggal 26 febuari 2015)

Zimmerer, W. Thomas And Norman M. Scarborough, (2002), "Pengantar
Kewirausahaan Dan Manajemen Bisnis Kecil", (Edisi Bahasa Indonesia) Alih Bahasa Edianan T. Sofia. Jakarta : PT. Rineka Cipta.

\section{Sumber Internet :}

As-Shofa (2010) dalam http://asshofa.or.id/_diakses pada tanggal 11 April 2017

Pertanian Universitas Gadjah Mada tahun 2008

(http://akademik.tp.ugm.ac.id), tugas pokok dan fungsi bagian akademik di perguruan tinggi. Diakses pada tanggal 12 April 2017.

Universitas Muhammadiyah Malang, dalam infoba UMM yang diakses pada tanggal 7 April 2017, 